http://www.jfas.info

\title{
KNOWLEDGE-BASED SYSTEM WITH ENHANCED SITUATIONAL AWARENESS, ANALYSIS FOR MALAYSIAN UN MILITARY OBSERVER (UNMO): A SOFTWARE DEVELOPMENT PERSPECTIVE
}

\author{
N.H.M. Daud*, S. Marzukhi and O. Zakaria \\ Department of Computer Science, Faculty of Defense Science and Technology, National \\ Defence University Malaysia, SgBesi Camp, 57000 Kuala Lumpur, Malaysia
}

Published online: 10 September 2017

\begin{abstract}
Nowadays, there are numerous of knowledge-based systems have been developed for military personnel involved in military missions. The existing system, nevertheless, none developed with situational awareness (SA) for Malaysian military personnel. The purpose of this paper is to invent a knowledge-based system with SA analysis that can be used by the Malaysian military personnel and later on, the system is integrated into rugged tablet or any pervasive equipment used in United Nation peacekeeping military operations. The system is created to assist military personnel, especially for military observer in decision-making when facing all possible scenarios based on United Nation peacekeeping military operation location and environment. This research will release a complete system of knowledge-based with SA analysis that emphasize to equip Malaysian observer in United Nation peacekeeping military operations.
\end{abstract}

Keywords: knowledge based system; situational awareness; system development; software development; data mining.

Author Correspondence, e-mail: nurhidayahdaud90@gmail.com

doi: http://dx.doi.org/10.4314/jfas.v9i3s.29 


\section{INTRODUCTION}

Situational awareness (SA) is the mental picture created by the continuous extraction of environment information and integration of the information with previous knowledge for predicting future perception and events [1]. SA can be mapped to many different areas including military since SA will improve operations, lead to better decision making and understanding of the current situation of environment [2].

Apart from being entirely dependent on the leader's knowledge of the mission, the military personnel normally equipped with military knowledge from numerous written doctrinal sources such as a training manual, guideline and set of trainings [3]. The possibility of having difficulties during military operations among military personnel is higher, especially when the location and environment is unfamiliar. Thus, sufficient knowledge related to the environment and its previous history is needed by the military personnel to overcome the difficulties and to reduce the risk in the mission.

The advancement of technology nowadays resulted excessive development of software and tool in order to assist military personnel during missions. Unfortunately, only few from the existing knowledge-based software and tool focus on SA specifically for Malaysian military personnel in missions. Valuable tacit knowledge acquired from the experience and expert during the military operations has never been properly documented for further reference. Tacit knowledge was first described by [4] where it said that the knowledge is acquired through practice and experience rather than through language [5].

Instead, Malaysian military personnel are rarely equipped with handheld devices and tools readily with knowledge-based system in hand that contain relevant information such as geo-political briefs, mandate study, patrolling techniques, negotiation and incident investigation, past cases to study and many others in order to assist the operations.

Therefore, the main objective of this research is to develop a knowledge-based system with enhancement of SA analysis interrelated to environment and location of United Nation peacekeeping military operations. Hence, the system and software will be integrated in the devices such as rugged tablet and smart watch to assist military personnel in decision making and knowledge enhancement. 


\subsection{Background}

United Nations Military Observers (UNMO) are military officers appointed to serve with the United Nations. Fig. 1 shows the official website of Malaysian Armed Force that illustrates current deployments in 7 missions.

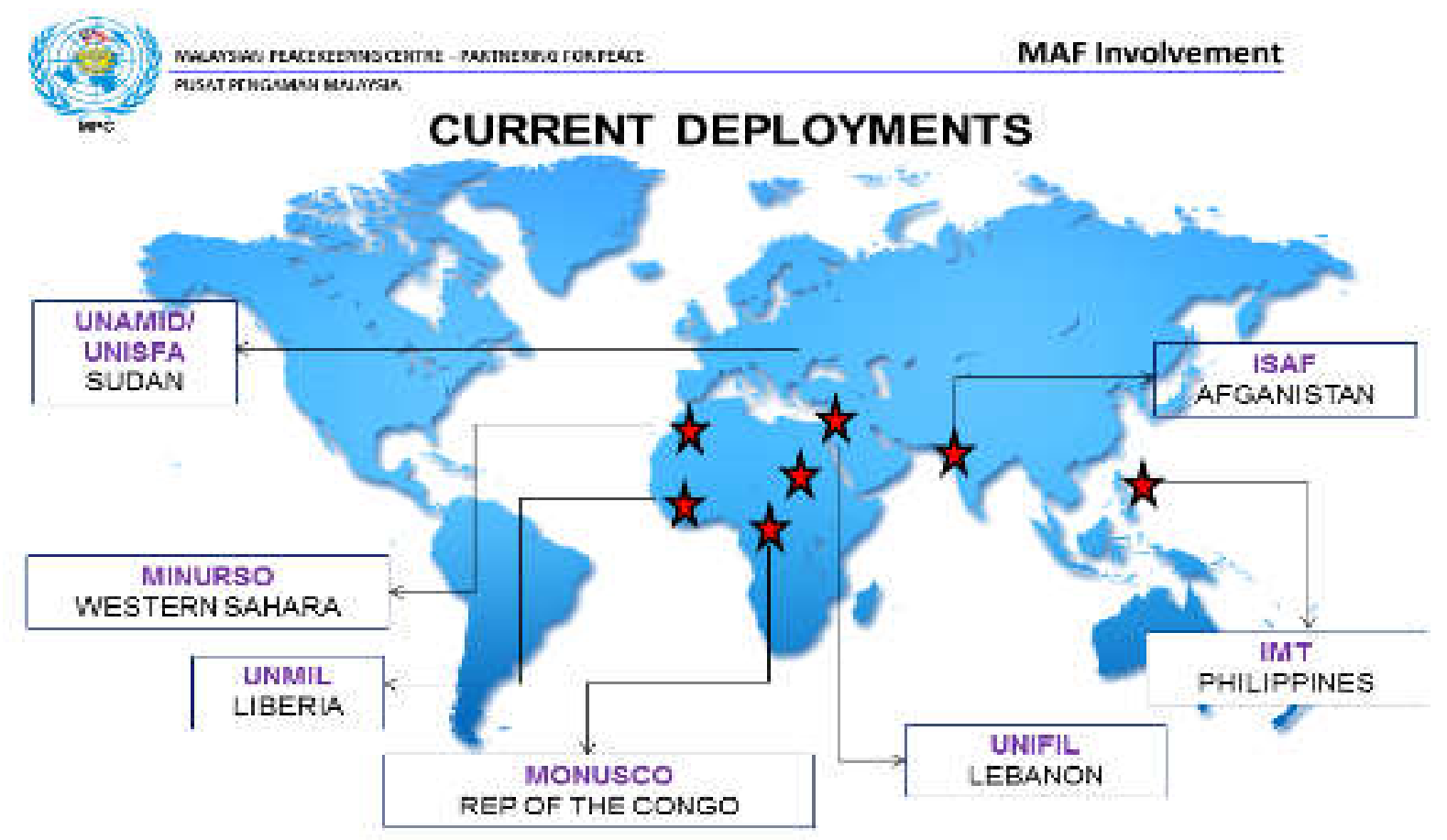

Fig.1. Malaysian current deployment [6]

United Nations Military Observers Handbook written by the United Nations Department of Peacekeeping Operation [7] has listed the tasks of UNMO as follows: 1) patrolling on foot by vehicle and using helicopters to gather the information by day and night in any terrain, 2) observing, monitoring and supervising agreements 3) negotiating in difficult or tense situations, through translators if necessary. In most conditions, the UNMO may live and work in situation of hardship and physical danger. Besides, UNMO will normally operate unarmed and they may assign either in team-base or among the local community.

Based on the interview sessions with former Malaysian military observers previously, Lt Col Dr Mohammad DaudJohari, there are several briefings, books, guidelines and notes are given to the UNMO before and during the mission. Since the task of the UNMO is to be the mediator and to solve tense or difficult situations among the local community, therefore, the knowledge, important information and in-depth understanding of the mission including previous and current conflicts, incidents and zone leaders are vital to them. In addition, the 
peacekeeping center encourages the UNMO to acquire the knowledge of the local language, negotiating skills and general historical background of the [4].

In order to extract the knowledge and identify hidden information pattern of the mission (e.g. conflicts, incidents and zone leaders) using data mining technique, data from reports, briefings, books, guidelines, notes and information gathered by the UNMO and other useful sources of the mission are needed. Based on preliminary study, only few studies are performed with extracting knowledge of the UN mission.However, none is conducted to assist UNMO. According to [8], for the last couple of decades, many organizations and companies have been using a database system in decision making.

This is due to the accessibility of data in real time that is extremely beneficial and contributes to positive impacts to the organizations and companies. Fig. 2 shows the Star Model developed by [8]. The model illustrates the impact of data to the organization from the different angle and perspectives, including people, strategy, structure, processes and rewards.

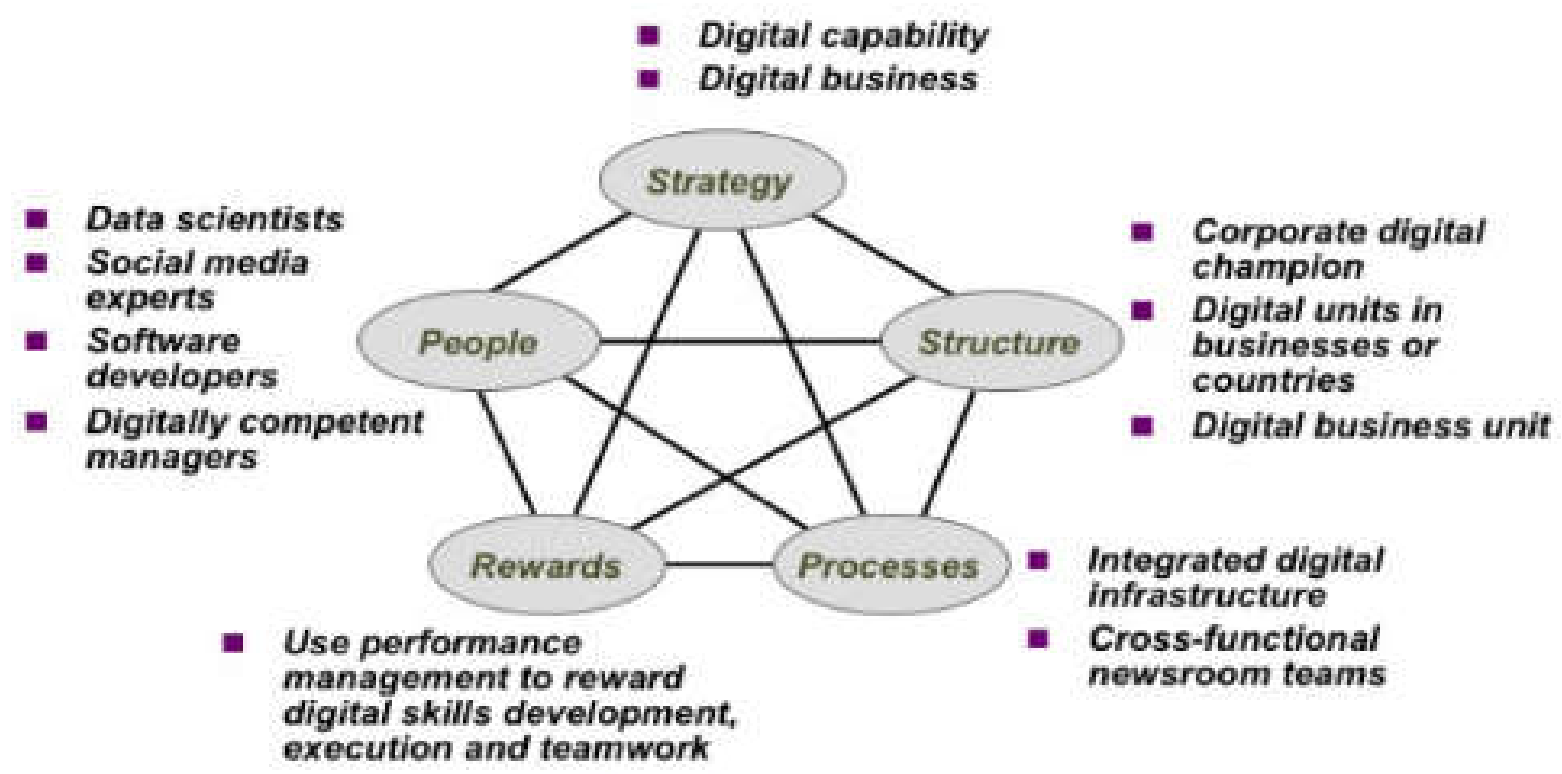

Fig.2. The Star Model to illustrate the impact of data [8]

The proposed knowledge-based system is significantly related to this research in order to represent knowledge that includes the tacit and explicit knowledge in a meaningful way. When knowledge is used, effectively shared and managed, it is very beneficial to efficient decision-making [9]. 


\section{EXPERIMENTAL}

This research consists of two parts: 1) knowledge extraction using data mining techniques and 2) the software development to assist Malaysian UNMO in peacekeeping missions.

\subsection{Knowledge Extraction Using Data Mining Technique}

The purpose of extracting knowledge from database and other resources is to provide sufficient beneficial knowledge related to the mission for the Malaysian UNMO.

Nowadays, data may contain from two types of data: 1) unstructured data such as photos, maps from a GPS device, videos, audio, emails, tweets and text messages from various sources, and 2) structured data which stored in rows and columns [8]. Data mining technique helps finding knowledge from raw, unprocessed data. Using data mining technique, knowledge can be extracted through the process of sorting and picking out meaningful and useful information from a large pool of data [9].

Here, the data warehouse will store data from various sources and transactions whereas the knowledge is extracted using the data mining technique in order to identify hidden information patterns. From the literature, there are numerous data mining techniques have been used for knowledge discovery from databases such as classification, clustering, association and prediction [9]. Table 1 shows various existing data mining techniques used to extract useful information and hidden relation of data in data mining researches. However, this research will only focus on two data mining technique: 1) clustering and 2) association rule.

Table 1. Various data mining techniques [10]

\begin{tabular}{cl}
\hline Data Mining Technique & \multicolumn{1}{c}{ Method } \\
\hline \multirow{2}{*}{ 1. Distance } \\
2. Decision trees \\
3. Fuzzy-sets \\
4. Neural networks \\
5. Support vector machine \\
1. Partitioning method (eg. K-Means Clustering) \\
Clustering
\end{tabular}




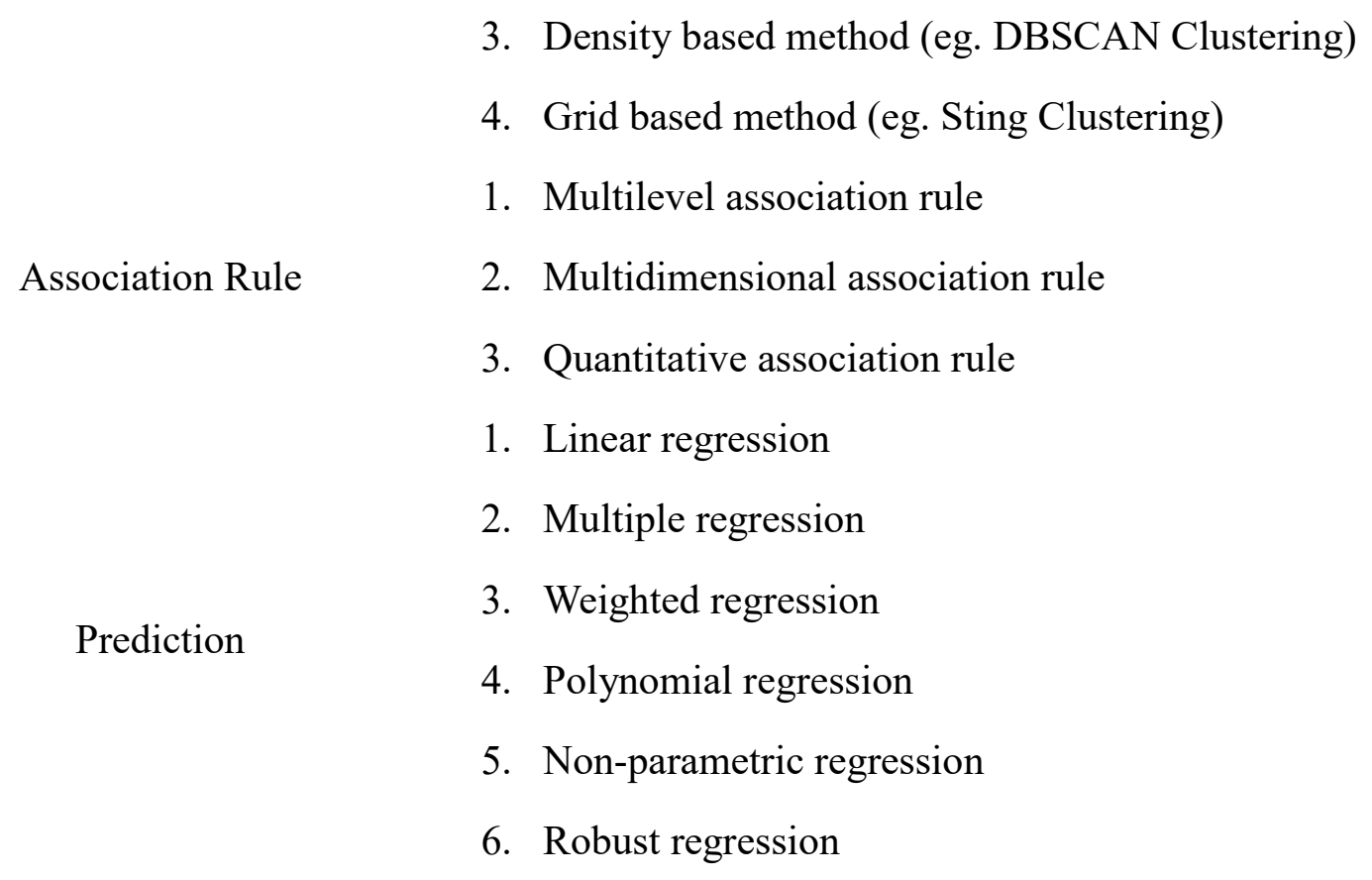

The Cross Industry Standard Process for Data Mining (CRISP-DM) model will be used in this research. The model comprises of 6 phases which are as follows: 1) business understanding, 2) data understanding, 3) data preparation, 4) modelling, 5) evaluation and 6) deployment. Fig. 3 shows the CRISP-DM model.

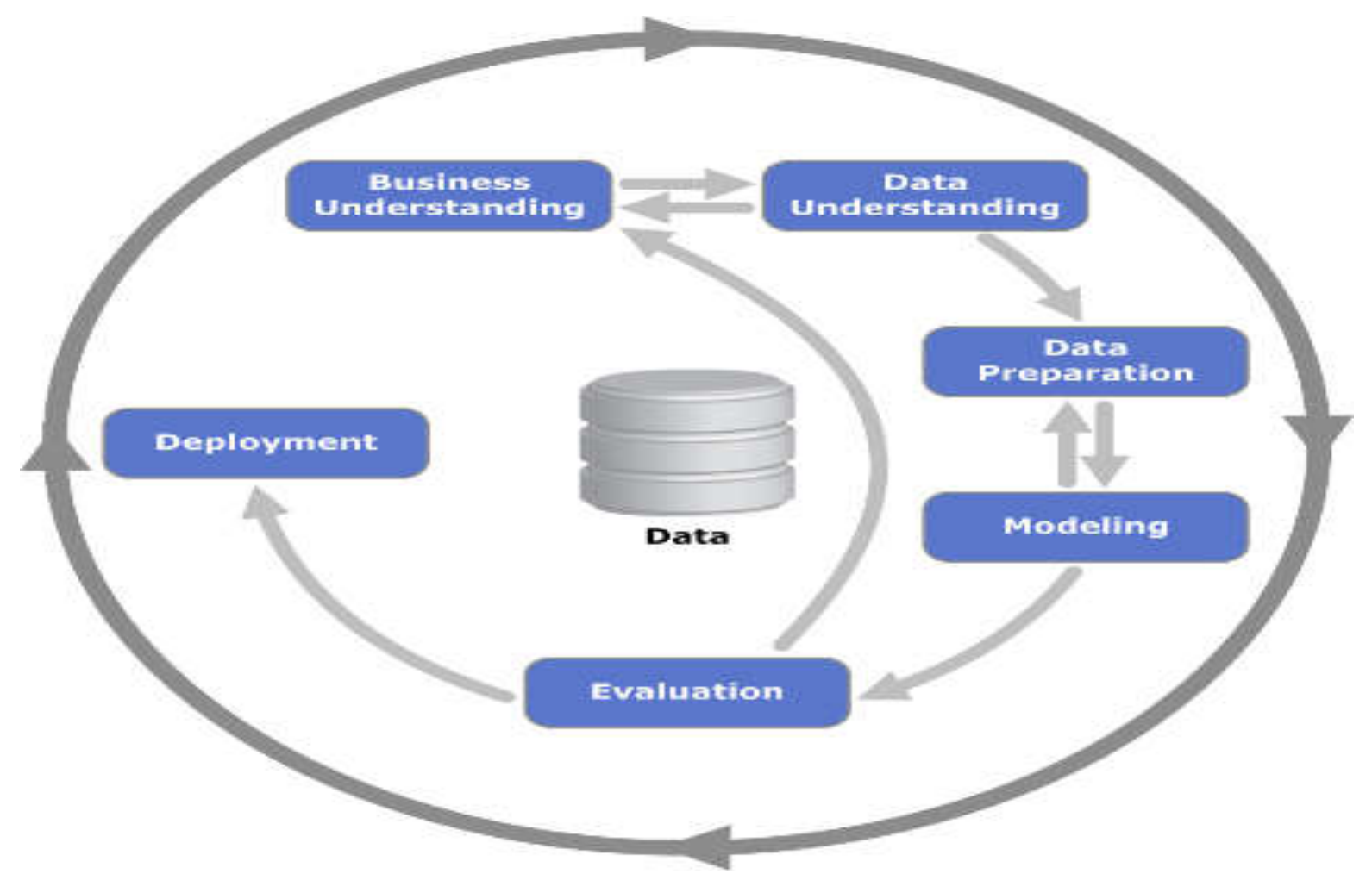

Fig.3. The CRISP-DM Model [11] 
In [11] describe the phases as follow:

- Business understanding phase focuses on the understanding of project objectives and requirements from a business perspective. Next, the information is converted to a data mining problem definition and a preliminary plan is designed to achieve the objectives.

- Data understanding phase collects and get familiar with the initial data that will be used to extract the knowledge and reveal the hidden beneficial information. Activities of identifying the data quality problem, discovering the first insights into the data and detecting interesting subsets to form a hypothesis regarding hidden patterns will be done.

- Data preparation tasks include the creating of table, record, attribution selection transformation and cleaning of data for modelling tools. This phase will be performed multiple times and not in any prescribed order.

- Various modelling techniques are selected and applied to the dataset in modelling phase. Some techniques have specific requirements on the form of a dataset. Thus, going back to the data preparation phase is often necessary.

- Evaluation phase is where the model and technique used to evaluate before deployment phase. The purpose of evaluation phase is to determine if there is any important business issue that has not been sufficiently considered. The decision of model and technique used should be acquired in this phase.

- Deployment phase depends on the requirements of the user. It can be as simple as generating a report or as complex as implementing a repeatable data mining process across the enterprise.

\subsection{Software Development to Present the Knowledge Extracted}

After the knowledge is extracted from the database to present the processed knowledge, the software is developed. The purpose of software development is to assist the Malaysian UNMO obtains beneficial knowledge for the mission to increase the speed of decision making among the Malaysian UNMO and the knowledge is used efficiently.

Information Systems Development Methodology (ISDM) is used as the guideline to develop the software. ISDM provides a consistent and repeatable workflow. ISDM presented the 
lifecycle associated with all systems development efforts including: 1) project scope, 2) conduct analysis, 3) define and design the solution, 4) create the system modules and 5) evaluate the system after its implementation. ISDM comprises 7 phases as follows: 1) business needs analysis, 2) scope definition, 3) requirements analysis, 4) design, 5) development, 6) integration, test and acceptance and 7) implementation and deployment. Fig. 4 shows the model of ISDM.

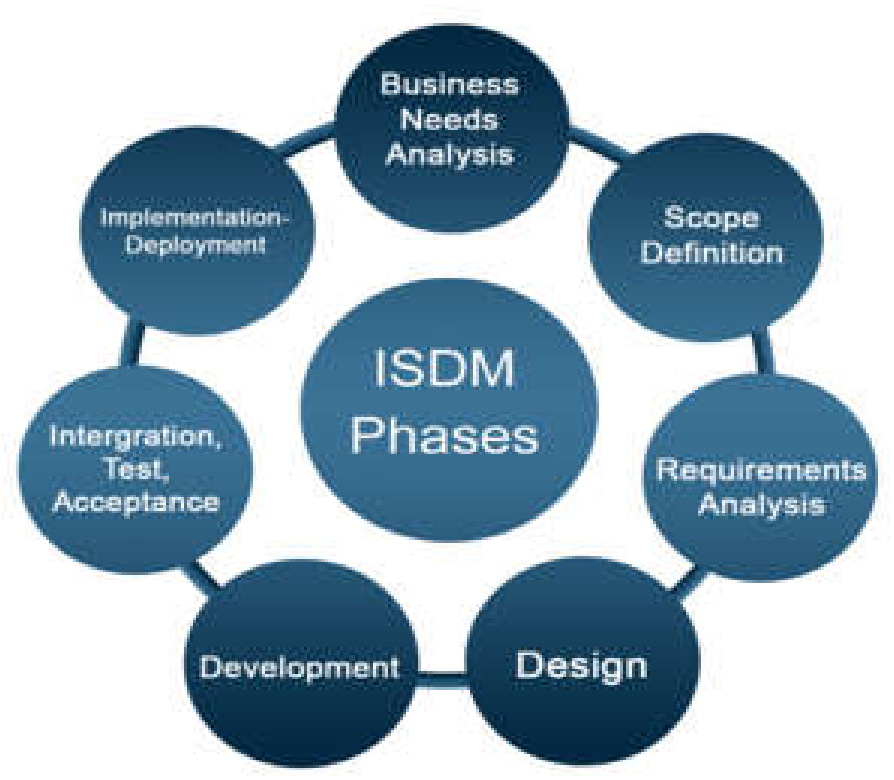

Fig.4. ISDM Model [16]

The phases are explained by the Florida Department of Financial Services Division of Information Systems [12] as below;

- Phase 1: Business needs analysis is performed such as identifying problems, opportunities, objectives and requirements from a business perspective. The outputs are information related to knowledge-based, SA and mission are reviewed.

- Phase 2: Comparative study of the research where the scope is defined. The research output of knowledge extracted that can suit customization of appropriate SA analysis into a knowledge-based system. Thus, assessment and prediction functions will be considered in enhancing the proposed knowledge-based system.

- Phase 3 and 4: The requirement analysis and the design of the software according to the needs of the Malaysian UNMO. 
- Phase 5: The output is coding analysis of SA components which are possible to be integrated into the knowledge-based software.

- Phase 6: System integration, testing and user acceptance will be done in this phase. A prototype is developed and tested. The visualization of SA components will be developed and real testing will be conducted, where the prototype will be reiterated and evaluated for the prototype fine-tuning. Based on the user acceptance test, the system with enhancing SA analysis will be reproduced and the process of prototype development will be reiterated in order to improve the system.

- Phase 7: The solution is deployed to the production environment. Here, all the project members confirm the system is functioning as expected in production. All users are notified and all appropriate system and user support documentation is distributed.

\section{RESULTS AND DISCUSSION}

The data mining technique helps to discover the pattern of hidden information and useful knowledge in raw data and other resources. For this research, only the suitable data mining technique of association rule mining and clustering will be explored to effectively extract the knowledge of the information in the database in order to provide sufficient knowledge to the UNMO in executing their mission. By means of the knowledge provided, this can help the UNMO in making decision during negotiations and the difficulties can control easily. Besides, the knowledge provided can help the UNMO for survival as they normally operate unarmed and live in physical danger.

The software developed through this research is to present the knowledge. Fig. 5 shows the collection of knowledge obtained and processed through a data mining technique will be stored in the database where it can be retrieved by the Malaysian UNMO. 


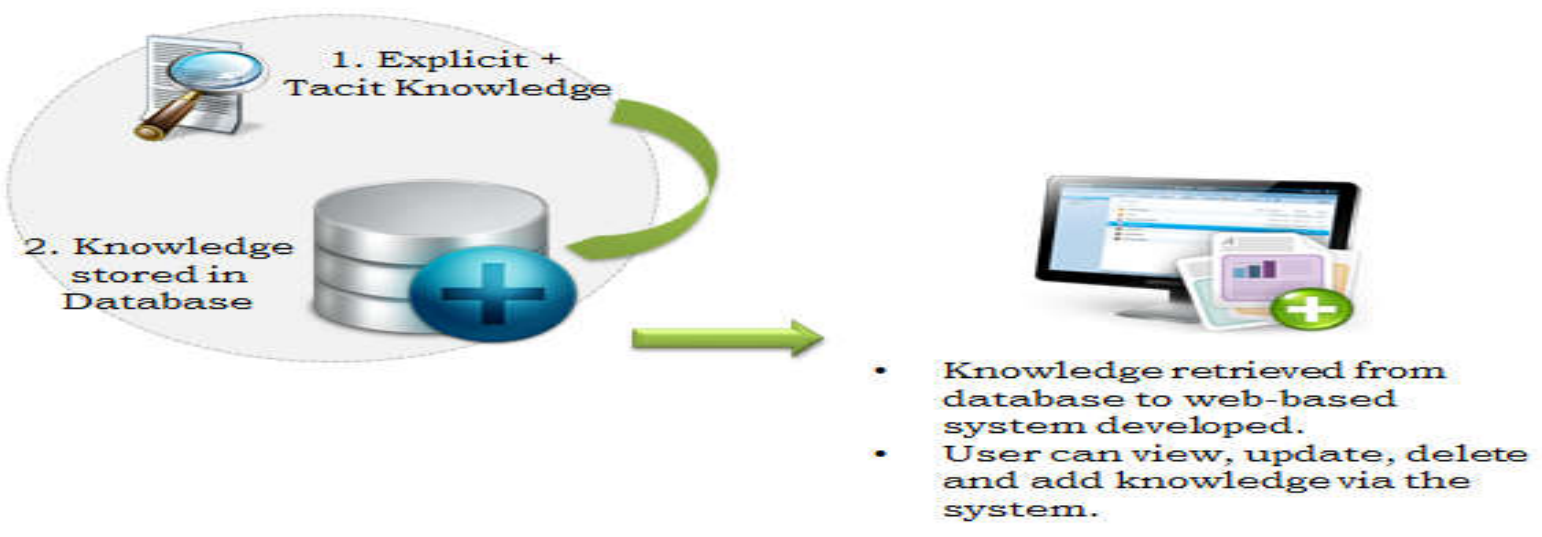

Fig.5. Software structure and design

The knowledge-based software consists of few modules. The main features of this module are: view and display existing knowledge, update and delete existing knowledge, add new knowledge (either tacit or explicit knowledge) via simple and user friendly interface. In order to ensure the authenticity of knowledge only authorize user can access this module specially to add new knowledge, where the administration need to check and approve the new knowledge.

In addition, the module has a unique functionality where both tacit and explicit knowledge are displayed in different method for retrieval. Details of related tacit and explicit knowledge will be displayed based on the keyword entered by the user. The knowledge presented is populated from the database. Therefore, the military personnelwill be equipped with adequate knowledge regarding the military operations including all the information in the training manual, user manual and doctrines that can be accessed at anytime from anywhere. Fig. 6 shows the interface of the software for the Malaysian UNMO. 


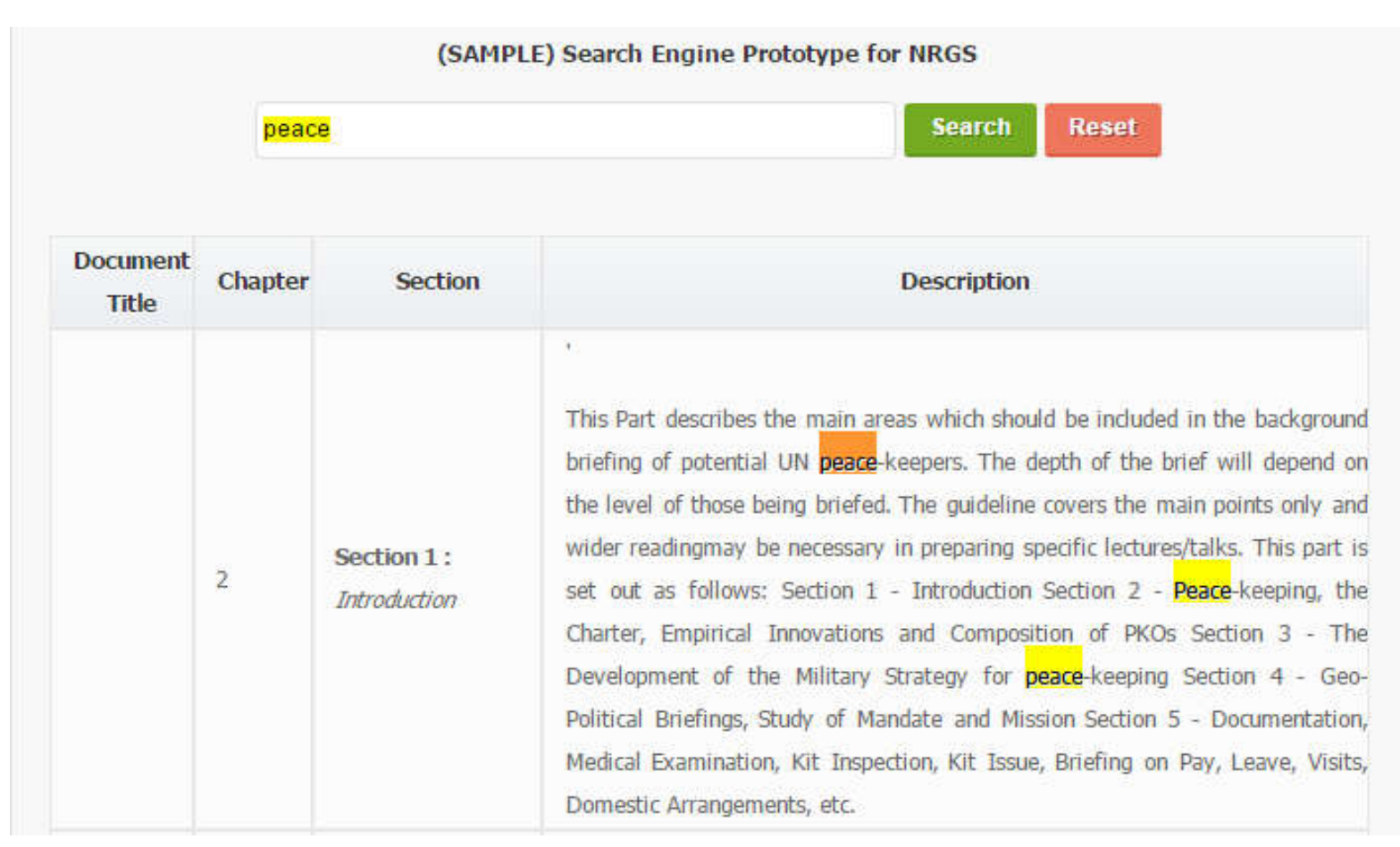

Fig.6. The interface of software

\section{CONCLUSION}

In any mission and military operations, the military personnel are exposed to danger in the mission area. Therefore, the military personnel are necessarily equipped with facilities and knowledge to keep them safe. Knowledge shortage among military personnel would obviously affect the decision-making in the critical situation. Thus, knowledge-based system with SA analysis resulted from this research, is recommended to be used later for military officer (e.g. military observers in United Nations operations, enhance the knowledge). The software has many benefits in the advancement of military personnel knowledge that has been extracted through the data mining techniques as follows: 1) database is designed to store valuable knowledge such as past experience, tragedy and actions taken for future reference, 2) demography of selected location is presented using a map with the indication facilities surround it for a particular location, 3) route planner 4) culture information 5) language and many more. Even though the complete system is not yet tested and integrated, but it seems promising to be implemented in helping military personnel to adapt to the environment of the military operation. 


\section{ACKNOWLEDGEMENTS}

This research funded under NRGS Research Grant (project code: NRGS/2013/UPNM/PK/P3). Thank you to the team members who provided insight and expertise that greatly assisted the research. We would also like to show our gratitude to the team members for sharing their pearls of wisdom with us during the course of this research.

\section{REFERENCES}

[1] Vidulich M, Vidulich M, Vogel E, Dominguez C, McMillan G. Situation awareness: Papers and annotated bibliography. Ohio: Armstrong Laboratory Wright-Patterson Air Force Base, 1994

[2] Hall M J, David H D, Jones K. Cross-domain situational awareness and collaborative working for cyber security. In IEEE International Conference on Cyber Situational Awareness, Data Analytics and Assessment, 2015, pp. 1-8

[3] Drozd J. Implementation possibilities of the military observer training to the training system for peacetime military engagement and peace support.Brno: University of Defence, 2013

[4] Polanyi M. The tacit dimension. Illinois: University of Chicago Press, 2009

[5] Kothari A, Rudman D, Dobbins M, Rouse M, Sibbald S, Edwards N. The use of tacit and explicit knowledge in public health: A qualitative study. Implementation Science, 2012, $7(1): 1-12$

[6] Garcia-Perez A, Shaikh S A, Kalutarage H K, Jahantab M. Towards a knowledge-based approach for effective decision-making in railway safety. Journal of Knowledge Management, 2015, 19(3):641-659

[7] United Nations Department of Peacekeeping Operation (UNDPO). United Nations military observers handbook. New York: UNDPO, 2001

[8] Galbraith J. Organization design challenges resulting from big data. Journal of Organization Design, 2014, 3(1):2-13

[9]Bâra A, Lungu I. Chapter 18: Improving decision support systems with data mining techniques. In A. Karahoca (Ed.), Advances in data mining knowledge discovery and 
applications.Rijeka: InTechOpen, 2012, pp. 400

[10] Gangurde P R A, Sonar P M R. Knowledge extraction using data mining techniques.Spvryan's International Journal of Engineering Sciences and Technology, 2014, $1(1): 1-4$

[11] Chapman P, Clinton J, Kerber R, Khabaza T, Reinartz T, Shearer C, Wirth R. Crisp-Dm 1.0. CRISP-DM Consortium.2000, http://www-staff.it.uts.edu.au/ paulk/teaching/dmkdd/ass2/readings/methodology/CRISPWP0800.pdf

[12] Florida Department of Financial Services Division of Information Systems (FDFSDIS). Information Systems Development Methodology (ISDM) version 1.10.Tallahassee: FDFSDIS, 2012

\section{How to cite this article:}

Daud N H M, Marzukhi S, Zakaria O. Knowledge-based system with enhanced situational awareness, analysis for malaysian un military observer (unmo): a software development perspective. J. Fundam. Appl. Sci., 2017, 9(3S), 360-372. 